ISSN: 2528-4002 (Media Online)

ISSN: 2355-892x (Print)

Online: http://e-journal.sari-mutiara.ac.id/index.php/KesehatanMasyarakat

DOI: https://doi.org/10.51544/jkmlh.v6i2.2415

\title{
PENGARUH SHIFT KERJA TERHADAP KELELAHAN KERJA PERAWAT DI UNIT RAWAT COVID-19 RSUD dr. DJASAMEN SARAGIH
}

\author{
Muhraza Siddiq ${ }^{1}$, Armanda Prima $^{2}$, Novrika Silalahi ${ }^{3 *}$, Ripai Siregar ${ }^{4}$, Sulastri Br Ginting ${ }^{5}$ \\ 1,2,3,4,5 Fakultas Kesehatan Masyarakat \\ Institut Kesehatan Deli Husada Deli Tua \\ E-mail: muhraza.siddiq@gmail.com \\ E-mail korespondensi : novrikasilalahi29@gmail.com
}

\begin{abstract}
Work weakness is portion of the common probelms that are regulary experienced within the work constrain, wearness can significantly affect the health of the workforce and can reduce productivity, including the nurse workforce. Fatigue is often caused by inappropriate working hours. Shift workers tend to be more prone to work burnout. Impactof work shift on nurse's work weakness in the unit covid-19 roomRSUD dr. Djasamen Saragih. The study used quantitative research with observational methods on 34 respondents. Univariat analysis showed that the majority of respondents experienced work fatigue, namely 20 people $(58.8 \%)$ and not tired of work, namely 14 people (41.2\%). From the results of the Bivariate analysis between work shifts and work weakness using the ChiSquare test, the p-value is 0.005 . With p-value $(0.005)<(0.05)$. This $H_{0}$ is rejected and $H_{1}$ is accepted. There's an effect of work shifts on the work fatigue of nurses in the Covid-19 Inpatient room at dr. Djasamen Saragih in 2021.
\end{abstract}

Keywords: nurse, work force, whorksift and whork fatigue

\section{PENDAHULUAN}

Berdasarkan UU RI No. 13 Tahun 2003 mengenai tenaga kerja pasal 86 menyatakan seluruh pekera atau buruh berhak mendapatkan jaminan atas keselamatan dan kesehatan, kesusilaan sertapenindakan yang sesuai dengan harkat dan martabat manusia serta norma agama dan sebagai perlindungan keselamatan tenaga kerja atau karyawan agar terwujudnya produktivitas maksimal dilakukan upaya K3 (UU RI No. 13 Tahun 2003). PermenKes 2013 disahkan bahwa masa kerja dibagi tiga, yakni pagi ke sore, sore ke malam atau malam ke pagi (Nur, 2019). lama kerja baiknya 7 jam/hari(40 jam/minggu) dan 8 jam/hari (40 jam/minggu) (Julia, 2017).

Penelusuran sebagian negara terlihat kelelahan(Fatingue) berperan terhadap kecelakaan kerja. Kelelahan berkontribusi 50\% teradap kecelakaan.

Epidemiolog Amerika Kennedy (1987), menyebutkan kelelahan kerja adalahsebuah kelainan yang selalu ditemuakn. Studi lain juga memaparkan jika kelelahan terkadang diakibatkan waktu kerjatidak sesuai. Pekerja cenderung lebih mudah lelah.Data(ILO) menyebutkan setiap tahun berkisar 2 juta pekerja meninggal akibat celaka dengan sebab kelelahan.(Karbito \&Oksandi, 2020).

Hasil pendataan 2018 oleh National Safety Concil, 2/3 pekerja Amerika merasakan lelah (Muller, 2020). Penelitian Kementerian Tenaga Kerja Jepang kepada 12.000 usha yang melibatkan hampir 16.000 karyawan menghasilkan sebanyak $65 \%$ mengalami kelelahan fisik akibat kerja, 28\% mengalami lelah mental dan 7\% stres berat serta merasa terasing (Munandar, Permatasari, \& Rezal, 2017).

Depnaker tahun 2014menjelaskan data kecelakaan kerja Indonesia perhari berkisar 414 kasus, dan 27,8\% akibat adri kelelahan yang tinggi (Mualin \& Yusmidiarti, 2019). The Joint Comission tahun 2008 memaparkan 300\% perawat salah melakukan tindakan karena lelah dan berakibat fatal terhadap pasien (Muis, Mulfiyanti, \&Rivai, 2019).

Dari survey awal di RSUD dr. Djasamen Saragih Simalungun Kecamatan Siantar Selatan Kota Pematangsiantar adalah pelayanan kesehatan yang beroperasi selama 24 jam setiap harinya dengan menerapkan sistem shift kerja. 
ISSN: 2528-4002 (Media Online)

ISSN: 2355-892x (Print)

Online: http://e-journal.sari-mutiara.ac.id/index.php/KesehatanMasyarakat

DOI: https://doi.org/10.51544/jkmlh.v6i2.2415

Berdasarkan uraian tersebut penulis membuat penelitian terhadap pengaruh shift kerja terhadap kelelahan perawat di Unit Rawat Covid RSUD dr. Djasamen Saragih Tahun 2021.

\section{METODE}

Jenis Penelitian

Penelitian menggunakan jenis kuantitatif metode Observasional jenis Cross Sectional karena memiliki variabel independen dan variabel dependen dalam satu waktu.

Lokasi penelitian ini dilakukan di Unit Rawat Covid RSUD dr.Djasamen Saragih pada bulan Desember 2020-Juni 2021.

Populasi yang digunakan merupakan perawat pada 4 unit ruang covid di RSUD dr. Djasamen Saragih Pematangsiantar dengan jumlah perawat 51 orang.

Pengambilan sample menggunakan random sampling desain Probability Sampling menggunakan Rumus Slovin.

\section{METODE PENGUMPULAN DATA \\ Data Primer}

Untuk data primer diperoleh dalam penelitian adalah dengan melakukan angket atau kuisioner, dimana kuesioner adalah teknik yang dilakukan dengan memberi beberapa pertanyaan tertulis kepada responden untuk dijawab.

\section{Data Sekunder}

Untuk data sekunder yang diperoleh dalam penelitian ini adalah melalui jurnal ataupun penelitian terdahulu yang berhubungan dengan permasalahan yang diteliti.

\section{Variabel dan Definisi Operasional Variabel Independen}

Tabel 1. Variabel Tidak terikat

\begin{tabular}{|c|c|c|c|c|}
\hline $\begin{array}{c}\text { Variabel } \\
\text { Independe } \\
n\end{array}$ & $\begin{array}{c}\text { Defenisi } \\
\text { Operasion } \\
\text { al }\end{array}$ & Alat Ukur & Kategori & Skala \\
\hline $\begin{array}{c}\text { Shift } \\
\text { Kerja } \\
\\
\text { (Pagi, } \\
\text { Sore, } \\
\text { Malam) }\end{array}$ & $\begin{array}{c}\text { Shift kerja } \\
\text { adalah } \\
\text { perbedaan } \\
\text { jam kerja } \\
\text { yang dibagi } \\
\text { menjadi } 3 \\
\text { kelompok, } \\
\text { yakni pagi, } \\
\text { sore dan } \\
\text { malam }\end{array}$ & $\begin{array}{c}\text { Kuesion } \\
\text { er }\end{array}$ & \begin{tabular}{|c} 
1.Pagi $(07.3$ \\
$0-14.00$ \\
WIB $)$ \\
2. Sore \\
$(13.30-$ \\
20.00 WIB $)$ \\
3. Malam \\
$(19.30-$ \\
08.00 WIB $)$
\end{tabular} & $\begin{array}{c}\text { Ordin } \\
\text { al }\end{array}$ \\
\hline
\end{tabular}

\section{Variabel Dependen}

Tabel 2. Variabel Terikat

\begin{tabular}{|c|c|c|c|c|}
\hline $\begin{array}{l}\text { Variabel } \\
\text { Denenden }\end{array}$ & Defenisi & Alat Ukur & Kategori & Skala \\
\hline $\begin{array}{l}\text { Kelelahan } \\
\text { Kerja }\end{array}$ & $\begin{array}{l}\text { Kelelahan } \\
\text { kerja adalah } \\
\text { keadaan } \\
\text { pekerja yang } \\
\text { dapat } \\
\text { menyebabkan } \\
\text { menurunnya } \\
\text { kesehatan } \\
\text { dan } \\
\text { produktivitas } \\
\text { pekerja } \\
\text { sebagai efek } \\
\text { dari } \\
\text { melakukan } \\
\text { pekerjaan }\end{array}$ & $\begin{array}{l}\text { KAUPK2 } \\
\text { (Kuesioner) }\end{array}$ & $\begin{array}{l}1 \\
\text { Tidak } \\
\text { Lelah } \leq \\
23 \\
2 \\
\text { Lelah }> \\
23\end{array}$ & Ordinal \\
\hline
\end{tabular}

\section{METODE ANALISIS DATA}

Pengolahan Data

Editing

Memeriksa kelengkapan dan kejelasan pengisian instrument pengumpuan data

1. Cleaning

Pengecekan agar tidak terdapat daya yang tidak di perlukan.

2. Tabulating (Pentabulasian)

Pengelompokan data sesuai tujuan penelitian yang akan dimasukkan kedalam tabel yang telah ditentukan skornya

3. Entry data (Memasukan Data)

Kegiatan memasukkan data kedalam tabel datau database computer.

\section{HASIL}

RSUD Dr. Djasamen Saragih berdiri tahun 1911oleh Perkebunan Marihat dengan nama "MARIHAT HOSPITAL". Direktur Utama Rumah Sakit pada waktu itu adalah Dr. Slotemaker.

RSUD dr. Djasamen Saragih Kota Pematangsiantar merupakan milik Pemerintah Pematangsiantar yang merupakan Rumah sakit tipe B ditetapkan MENPAN RI No. B1267/I/1992 dan SKMenKes RI No.1070/Menkes/SK/XI/XI/1992dan SK Gubernur Sumatera Utara No. 445/3155/K/1992 
ISSN: 2528-4002 (Media Online)

ISSN: 2355-892x (Print)

Online: http://e-journal.sari-mutiara.ac.id/index.php/KesehatanMasyarakat

DOI: https://doi.org/10.51544/jkmlh.v6i2.2415

\section{Karakteristik Responden}

Sampel penelitian ini adalahperawat di Rumah Sakit Umum Daerah dr. Djasamen Saragih, dengan 34 Perawat. Karakteristik responden yang diteliti terdiri dari : Jenis kelamin, Pendidikan, Usia, dan Status Kepegawaian.

Tabel 4.1Distribusi Karakteristik perawat Covid19 RSUD dr. Djasamen Saragih Kota Pematangsiantar Tahun 2021

\begin{tabular}{|c|c|c|}
\hline NO Variabel & Frekuensi & $\%$ \\
\hline \multicolumn{3}{|l|}{ Jenis Kelamin } \\
\hline 1 Laki-laki & 14 & 41,2 \\
\hline 2 Perempuan & 20 & 58,8 \\
\hline Total & 34 & 100 \\
\hline \multicolumn{3}{|l|}{ Pendidikan } \\
\hline 1 D3 Keperawatan & 19 & 55,9 \\
\hline 2 S1 Keperawatan & 10 & 29,4 \\
\hline 3 Profesi Ners & 5 & 14,7 \\
\hline Total & 34 & 100 \\
\hline \multicolumn{3}{|l|}{ Usia } \\
\hline $121-30$ Tahun & 12 & 35,3 \\
\hline 2 31-40 Tahun & 18 & 52,9 \\
\hline $3>40$ Tahun & 4 & 11,8 \\
\hline Total & 34 & 100 \\
\hline \multicolumn{3}{|l|}{ Status Pegawai } \\
\hline 1 Pegawai Kontrak & 26 & 76,5 \\
\hline 2 Pegawai Tetap & 8 & 23,5 \\
\hline Total & 34 & 100 \\
\hline
\end{tabular}

Menurut tabel diatas, pada variabel jenis kelamin mayoritas perawat perempuan yaitu 20 $(58,8 \%)$, sebaliknya sebanyak 14 orang berjenis kelamin laki-laki $(41,2 \%)$.

Karakteristik responden berdasarkan pendidikan dapat dilihat bahwa mayoritas pendidikan responden adalah D-III Keperawatan yaitu 19 orang $(55,9 \%)$ dan minoritas adalah Profesi Ners yaitu 5 orang $(14,7 \%)$.

Karakteristik responden berdasarkan usia dapat dilihat bahwa mayoritas usia responden adalah kelompok usia 31-40 tahun yaitu 18 orang $(52,9 \%)$ dan minoritas adalah kelompok usia $>40$ tahun yaitu 4 orang $(11,8 \%)$.

Karakteristik responden berdasarkan status pegawai dapat dilihat bahwa mayoritas adalah berstatus pegawai kontrak yaitu 26 orang $(76,5 \%)$ dan 8 pearwat berstatus pegawai tetap $(23,5 \%)$.

\section{Analisis Univariat}

Tabel 4.2 sebaran Shift Kerja dan Kelelahan Kerja di Ruang Rawat Inap Covid-19 RSUD dr. Djasamen Saragih

\begin{tabular}{|c|c|c|c|}
\hline NO & Shift Kerja & Fr & \\
\hline 1 & Pagi & 16 & 47,1 \\
\hline 2 & Sore & 10 & 29,4 \\
\hline 3 & Malam & 8 & 23,5 \\
\hline & Total & 34 & 100 \\
\hline & Kelelahan K & & \\
\hline 1 & Lelah & 20 & 58,8 \\
\hline 2 & Tidak Lelah & 14 & 41,2 \\
\hline & Total & 34 & 100 \\
\hline
\end{tabular}

Dari tabel diatas distribusi berdasarkan shift kerja dapat dilihat bahwa mayoritas responden adalah shift kerja pagi yaitu 16 orang $(47,1 \%)$ dan minoritas adalah shift kerja malam yaitu 8 orang $(23,5 \%)$. Distribusi responden berdasarkan kelelahan kerja dapat dilihat bahwa mayoritas responden adalah lelah kerja yaitu 20 orang $(58,8 \%)$ dan minoritas adalah tidak lelah kerja yaitu 14 orang $(41,2 \%)$.

Analisis Bivariat

Tabel 4.3 Tabulasi Shift Kerja dan Kelelahan Kerja

$$
\text { Kelelahan Kerja }
$$

\begin{tabular}{|c|c|c|c|c|c|c|c|}
\hline \multirow[t]{2}{*}{$\begin{array}{l}\text { Shift } \\
\text { Kerja }\end{array}$} & \multicolumn{2}{|c|}{ Lelah } & \multicolumn{2}{|c|}{$\begin{array}{l}\text { Tidak } \\
\text { Lelah }\end{array}$} & \multicolumn{2}{|c|}{ Total } & \multirow[t]{2}{*}{ P value } \\
\hline & $\mathbf{n}$ & $\%$ & $n$ & $\%$ & & $\%$ & \\
\hline 1 Pagi & 14 & 41,2 & 2 & 5,9 & 16 & 47,1 & \\
\hline 2 Sore & 4 & 11,8 & 6 & 17,6 & 10 & 29,4 & \\
\hline 3 Malam & 2 & 5,9 & 6 & 17,6 & 8 & 23,5 & 0,005 \\
\hline Total & 20 & 58,8 & 14 & 41,2 & 34 & 100 & \\
\hline
\end{tabular}

Berdasarkan tabel diatas diketahui shift kerja pagi dengan lelah kerja sejumlah 14 orang $(41,2 \%)$, shift kerja pagi dengan tidak lelah kerja sejumlah 2 orang $(5,9 \%)$. Untuk shift kerja sore dengan lelah kerja sejumlah 4 orang $(11,8 \%)$, shift kerja sore dengan tidak lelah kerja sejumlah 6 orang $(17,6 \%)$. Untuk shift kerja malam dengan lelah kerja sejumlah 2 orang $(5,9 \%)$, shift 
ISSN: 2528-4002 (Media Online)

ISSN: 2355-892x (Print)

Online: http://e-journal.sari-mutiara.ac.id/index.php/KesehatanMasyarakat

DOI: https://doi.org/10.51544/jkmlh.v6i2.2415

kerja malam dengan tidak lelah kerja sejumlah 6 orang $(17,6 \%)$. Dari hasil analisis antara shift kerja terhadap kelelahan kerja dengan ChiSquare dengan nilai $\mathrm{p}=0,005$.

\section{PEMBAHASAN}

Shift Kerja Perawat di Ruang Rawat Inap Covid-19 RSUD dr. Djasamen Saragih Pematangsiantar Tahun 2021

Berdasarkan hasil penelitian untuk shift kerja didapatkan shift kerja pagi menjadi shift kerja yang lebih tinggi yaitu 16 orang $(47,1 \%)$ kemudian shift sore 10 orang $(29,4 \%)$ dan shift malam 8 orang $(23,5 \%)$. Sebagian besar perawat mengatakan mereka mendapatkan long play dan pekerjaan yang banyak pada saat shift pagi. Dari 16 perawat yang mendapatkan shift pagi, $60 \%$ menjawab dengan banyak nya aktivitas dan pekerjaan di jam pagi, mereka tidak punya jam istirahat yang cukup dan tidak ada waktu untuk bersantai atau merilekskan badan dan 50\% perawat mereka dilarang untuk beristirahat terlalu lama karena mereka sedang menjaga pasien yang siaga selama 24 jam dan terkadang tekena longplay dikerenakan kurangnya jumlah perawat covid di ruangan. Sementara dari kelompok shift siang menyatakan bahwa mereka tetap mendapatkan pekerjaan yang banyak tetapi tidak sebanyak pada saat shift pagi, karena sebagian pekerjaan sudah diselesaikan oleh perawat yang bekerja di shift pagi.

Dari kelompok shift malam 2 dari 10 orang mengatakan mereka biasanya hanya menjaga pasien dan tidak banyak melakukan pekerjaan yang berat sehingga mempunyai waktu istirahat yang lumayan cukup. Hasilnya sejalan dengan penelitian Alawiyyah (2019) menyimpulkan sebagian besar perawat paling sedikit mendapatkan waktu istirahat adalah pekerja shift pagi.

Kelelahan Kerja Perawat di RRI Covid RSUD dr. Djasamen Saragih Kota Pematangsiantar Tahun 2021

Hasil analisis univariat menunjukkan mayoritas responden mengalami lelah kerja yaitu 20 orang $(58,8 \%)$ dan tidak lelah kerja yaitu 14 orang $(41,2 \%)$. Hal ini diakibatkan oleh banyaknya pekerjaan yang harus disiapkan. Kehilangan konsentrasi dalam jangka waktu yang cepat menunjukkan bahwa para perawat mengalami kelelahan kerja pada perawat. Pada kelompok shift pagi mereka lebih di tuntut untuk lebih fokus terhadap pekerjaan.

Penelitian yang dilakukan oleh Akbar Insani (2018), terkait Pengaruh Tingkat kejenuhuan terhadap kinerja Perawat menjelaskan bahwa perawat mengalami kejenuhan terkait pekerjaannya sehingga menyebabkan kelelahan dalam melakukan tindakan kepada pasien dan dapat menurunkan kinerja para perawat.

Penelitian yang berkaitan dengan hal ini yakni oleh Muizzudin (2019) mengatakan 14 pekerja $(50,0 \%)$ mengalami kelelahan, 10 pekerja $(35,7 \%)$ kelelahan sedang dan 4 pekerja $(14,3 \%)$ kelelahan ringan. Muizziudin mengatakan kelelahan kerja merupakan respon tubuh karena terlalu lama mengerjakan suatu pekerjaan.

Penelitian yang dilaksanakan oleh Agnes Ferusgel (2016), mengenai Faktor yang Mempengaruhi Kelelahan Fisik KerjaPada Pekerja Molding Plantdi PT. Pacific Medan Industri menyatakan bahwa para pekerja mengalami kelelahan kerja fisik yang dipengaruhi oleh beban kerja yang menyebabkan perlu dilakukan penanganan lebih lanjut agar kelelahan pada pekerja dapan dikontrol sehingga produktivitas dan efektifitas kerja tidak menurun.

\section{Pengaruh Shift Kerjaterhadap Kelelahan Kerja Perawat di RRI Covid RSUD dr. Djasemen Saragih Kota Pematangsiantar Tahun 2021}

Hasil Penelitian didapatkan shift kerja pagi dengan lelah kerja sejumlah 14 orang $(41,2 \%)$, shift kerja pagi dengan tidak lelah kerja sejumlah 2 orang $(5,9 \%)$. Untuk shift kerja sore dengan lelah kerja sejumlah 4 orang $(11,8 \%)$, shift kerja sore dengan tidak lelah kerja sejumlah 6 orang $(17,6 \%)$. Untuk shift kerja malam dengan lelah kerja sejumlah 2 orang (5,9\%), shift kerja malam dengan tidak lelah kerja sejumlah 6 orang $(17,6 \%)$. Dari hasil analisis antara shift kerja terhadap kelelahan kerja memakai uji ChiSquare dengan nilai $\mathrm{P}=0,005$.

Dari hasil analisis antara shift kerja terhadap kelelahan kerja dengan Chi-Square dengan $\mathrm{p}=0,005$. Dengan $\mathrm{p}$-value yaitu $(0,005)<$ 
ISSN: 2355-892x (Print)

Online: http://e-journal.sari-mutiara.ac.id/index.php/KesehatanMasyarakat

DOI: https://doi.org/10.51544/jkmlh.v6i2.2415

$\alpha(0,05)$. Dengan demikian $\mathrm{H}_{0}$ ditolak dan $\mathrm{H}_{1}$ diterima yang berarti terdapatpengaruh shift terhadap kelelahan kerja perawat covid-19 di RSUD dr. Djasamen Saragih.

Pada tulisan ini, shift kerja pagi adalah shift kerja yang memiliki tingkat kelelahan kerja yang tinggi terhadap perawat, hal ini disebabkan karena kurangnya jumlah perawat. Pergantian shift merupakan salah satu sebab terjadinya kelelahan kerja pada perawat covid, yang dimana terkadang shift malam ke shift pagi. Banayaknya pekerjaan yang harus dilakukan perawat pada jadwal pagi ditambah dengan banyaknya pasien yang keluar (sehat) dan masuk cukup banyak. Hasil dari pengukuran didapat kelelhan perawat paling tinggi terjadi pada pagi hari.

Penelitian ini didukung oleh Rusdi dan Bambang Edi Warsito dari hasil uji Chi Square menunjukkan bahwa shift kerja pagi merupakan tingkat paling dominan yang memiliki pengaruh terhadap kelelahan kerja dengan nilai $\mathrm{p}=0,030$ $<\alpha=0,005$.

Akan tetapi hasil penelitian bertolakbelakang dengan Fatona Lusidari hasil uji Kruskal Wallis menunjukkan bahwa shift kerja pagi merupakan tingkat paling rendah yang memiliki tingkat pengaruh terhadap kelelahan kerja, sedangkan shift kerja yang paling memiliki tingkat pengaruh paling dominan adalah shift malam dengan $p=0,038<\alpha=0,005$.

\section{KESIMPULAN}

Mayoritas shift kerja perawat covid-19 di RSUD dr. Djasamen 2021 adalah shift pagi yaitu 16 orang atau $47,1 \%$ dari 34 responden dengan mayoritas mengalami lelah kerja yaitu 20 orang atau $58,8 \%$ dari 34 responden dan terdapat pengaruh shift kerja terhadap kelelahan kerja di rawat inap covid-19 di RSUD dr. Djasamen Saragih 2021 dengan p value $(0,005)$.

\section{UCAPAN TERIMAKASIH}

Terimakasih saya ucapkan kepada orang tua yang selalu memberikan dorongan untuk kemajuan saya, terima kasih kepada Institusi dan tempat penelitian saya yang memberikan tempat dan waktu untuk kegiatan penelitian ini. Kegiatan penelitian ini tidak mengandung unsur konflik terhadap pihak-pihak atau lembaga tertentu dan tidak adanya kepentingan yang dapat merugikan orang lain.

\section{DAFTAR PUSTAKA}

Akbar Insani, D., Lestari, S., Nasution, R., Erawati, S., \& Ginting, R. (2018). Pengaruh Tingkat Kejenuhan Terhadap Kinerja Perawat Wanita Di Ruang Rawat Inap Rumah Sakit Umum Royal Prima Tahun 2018. In Jurnal Mutiara Kesehatan Masyarakat (Vol. 3, Issue 1).

Belia, M. N. (2020). Hubungan Antar Kerja Shift dengan Kelelahan Akibat Kerja pada Perawat Bangsal Anak dan Penyakit Dalam di Lingkungan RSMP. Universitas Muhamadiyah Palembang.

Penelitian Tentang Kelelahan Kerja. (2021). Canadian Nurse Association.

Dewi, B. M. (2018). Hubungan Antara Motivasi, Beban Kerja, Dan Lingkungan Kerja Dengan Kelelahan Kerja. The Indonesian Journal Of Occupational Safety And Health, 7.

Fatona, L. (2015). Perbedaan Tingkat Kelelahan Antara Shift Pagi, Sore, dan Malam pada Perawat Rawat Inap di RS PKU AISYIYAH Boyolali. Universitas Muhammadiyah Boyolali.

Ferusgel, A. (2018). Faktor Yang Mempengaruhi Kelelahan Fisik Kerja Pada Pekerja Molding Plant Di Pt. Pacific Medan Industri Tahun 2016. Jurnal Kesehatan Masyarakat Dan Lingkungan Hidup, 1(1), 32-38.

Hamel, Rivelino S. 2018. E-journal Perbedaan Tingkat Kelelahan Kerja Perawat di Unit Gawat Darurat dan Poliklinik Rumah Sakit Umum GMIM Pancaran Kasih Manado. Universitas Sam Ratulangi: Manado. 
ISSN: 2355-892x (Print)

Online: http://e-journal.sari-mutiara.ac.id/index.php/KesehatanMasyarakat

DOI: https://doi.org/10.51544/jkmlh.v6i2.2415

Hijriani, N. (2017). Skripsi Analisis Tingkat

Kelelahan Kerja Perawat di Ruang UGD

RSPUNHAS dan RSUP dr. Wahidin

Sudirohusodo. Universitas Islam Negeri

Alauddin Makassar.

International Labor Organization (ILO)

2014Tentang Data Kecelakaan Kerja

Kennedy.1998. "Studi Epidemiologi”. Amerika

Serikat.

Kepmenakertrans RI Nomor : KEP. 224/MEN/2003 Tentang Waktu Kerja dan Istirahat. Jakarta: Indonesia.

Kusumawardani, L. (2012). Pengaruh Shift

Kerja Terhadap Kelelahan Kerja Perawat

Wanita Bagian Rawat Inap di Rumah Sakit

$d r$. Oen Surakarta. Universitas Sebelas

Maret.

Pramitasari, R. M. (2016). Pengaruh Masa Kerja dan Shift Kerja Terhadap Kelelahan Kerja pada Perawat Inap di Rumah Sakit PKU Muhammadiyah. Universitas

Muhammadiyah Surakarta.

Rhamdani, I., \& Wartono, M. (2019). Hubungan Antara Shift Kerja, Kelelahan Kerja Dengan Stres Kerja Pada Perawat. Jurnal Biomedika Dan Kesehatan, 2(3), 104-110.

Trinofiandy, R. (2018). Hubungan Karakteristik Individu, Shift Kerja, dan Masa Kerja dengan Kelelahan Kerja Pada Perawat di Rumah Sakit X Jakarta Timur. Universitas Respati Indonesia.

Undang-Undang RI No. 13 Tahun 2003 Tentang Ketenagakerjaan. Jakarta:Indonesia

Undang-Undang RI No. 38 Tahun 2014.Tentang Keperawatan.Jakarta:Indonesia.

Undang-Undang RI No.36 Tahun 2009 Tentang Kesehatan. Jakarta: Indonesia. 